Note: This is a preprint of paper being submitted for publication. Contents of this paper should not be quoted nor referred to without permission ot the author(s).

Submitted to: SPIE Conference "Oxide

Superconductors: Physics and Nanoengineering II,"

January 27-February 2, 1996

\title{
Formation and Properties of Novel Artificially-Layered Cuprate Superconductors Using Pulsed-Laser Deposition
}

D. P. Norton, B. C. Chakoumakos, and J. D. Budai

"The submitted manuscript has been authored by a contractor of the U.S. Government under contract DE-AC05-960R22464. Accordingly, the U.S. Government retains a nonexclusive, royalty-free license to publish or reproduce the published form of this contribution, or allow others to do so, for U.S. Government purposes."

March 1996

Prepared by Solid State Division

Oak Ridge National Laboratory P.O. Box 2008

Oak Ridge, Tennessee 37831-6056 managed by

LOCKHEED MARTIN ENERGY RESEARCH CORP. for the U.S. DEPARTMENT OF ENERGY under contract DE-AC05-96OR22464
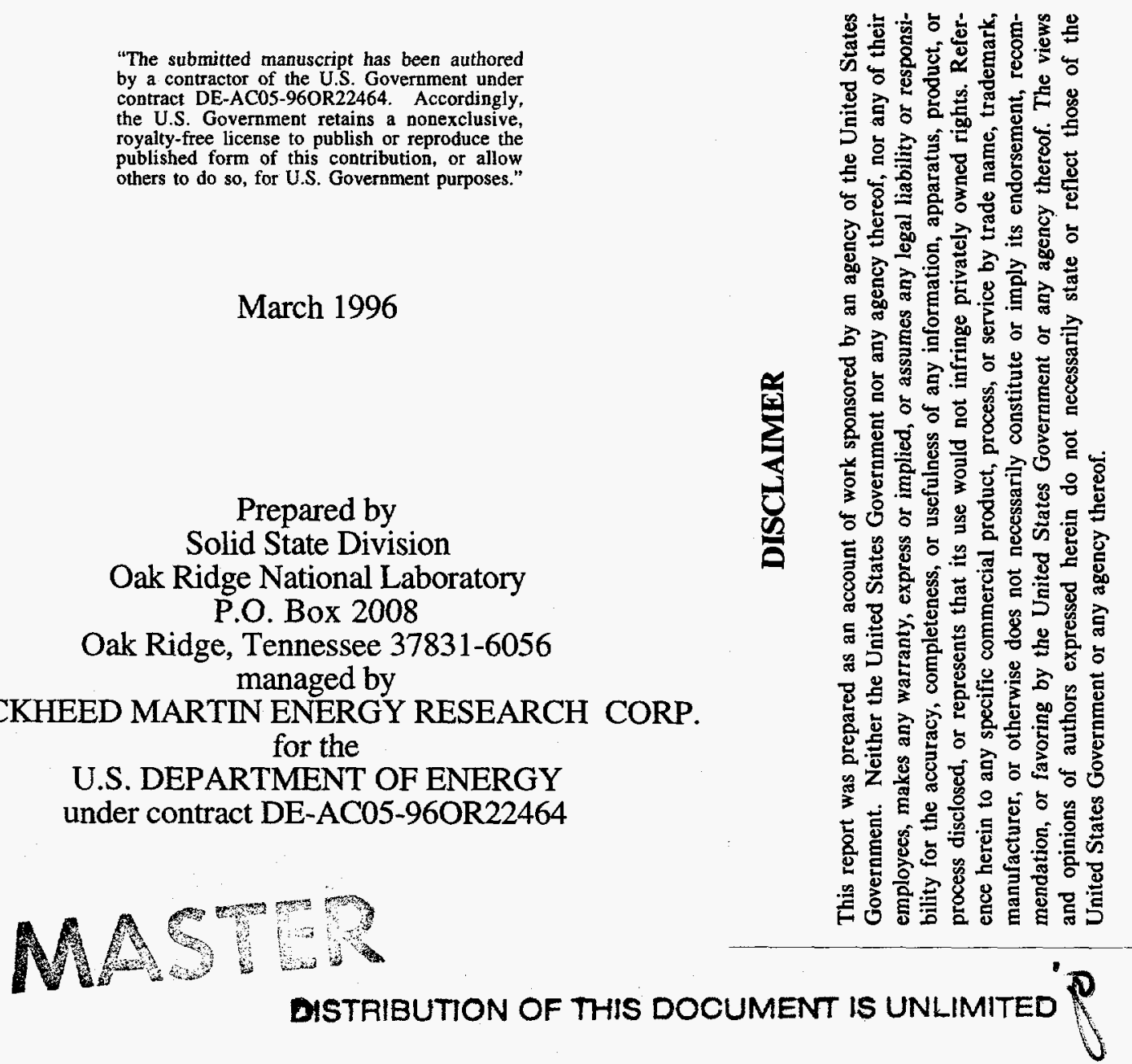


\section{DISCLAIMER}

Portions of this document may be illegible in electronic image products. Images are produced from the best available original document. 
Formation and properties of novel artificially-layered cuprate superconductors using pulsed-laser deposition

D. P. Norton, B. C. Chakoumakos and J. D. Budai

Solid State Division, Oak Ridge National Laboratory, Oak Ridge, TN 37831-6056

\section{ABSTRACT}

Pulsed-laser deposition and epitaxial stabilization have been effectively used to engineer artificially-layered thin-film materials. Novel cuprate compounds have been synthesized using the constraint of epitaxy to stabilize $(\mathrm{Ca}, \mathrm{Sr}) \mathrm{CuO}_{2} /(\mathrm{Ba}, \mathrm{Ca}, \mathrm{Sr}) \mathrm{CuO}_{2}$ superconducting superlattices in the infinite layer structure. Superlattice chemical modulation can be observed from the $\mathrm{x}$-ray diffraction patterns for structures with $\mathrm{SrCuO}_{2}$ and $(\mathrm{Ca}, \mathrm{Sr}) \mathrm{CuO}_{2}$ layers as thin as a single unit cell $(\sim 3.4 \AA)$. X-ray diffraction intensity oscillations, due to the finite thickness of the film, indicate that $(\mathrm{Ca}, \mathrm{Sr}) \mathrm{CuO}_{2}$ films grown by pulsed-laser deposition are extremely flat with a thickness variation of only $\sim 20 \AA$ over a length scale of several thousand angstroms. This enables the unit-cell control of $(\mathrm{Ca}, \mathrm{Sr}) \mathrm{CuO}_{2}$ film growth in an oxygen pressure regime in which in situ surface analysis using electron diffraction is not possible. With the incorporation of $\mathrm{BaCuO}_{2}$ layers, superlattice structures have been synthesized which superconduct at temperatures as high as $70 \mathrm{~K}$. Dc transport measurements indicate that $(\mathrm{Ca}, \mathrm{Sr}) \mathrm{CuO}_{2} / \mathrm{BaCuO}_{2}$ superlattices are two dimensional superconductors with the superconducting transition primarily associated with the $\mathrm{BaCuO}_{2}$ layers. Superconductivity is observed only for structures with $\mathrm{BaCuO}_{2}$ layers at least two unit cells thick with $T_{c}$ decreasing as the $(\mathrm{Ca}, \mathrm{Sr}) \mathrm{CuO}_{2}$ layer thickness increases. Normalized resistance in the superconducting region collapse to the Ginzburg-Landau Coulomb gas universal resistance curve consistent with the two-dimensional vortex fluctuation model.

KEY WORDS: superlattices, artificially-layered epitaxy, infinite layer, vortex fluctuations

\section{INTRODUCTION}

Since the discovery of high-temperature superconductivity (HTSc), ${ }^{1}$ intensive efforts have revealed numerous families of layered crystal structures containing copper oxide layers, ${ }^{2}$ with superconducting transition temperatures as high as $135 \mathrm{~K}$ for the $\mathrm{Hg}$-containing cuprates ${ }^{3}$. Typically, bulk synthesis techniques have been the primary tool in the search for new HTSc materials. Recently, high-pressure synthesis methods have played a prominent role in making metastable cuprate phases. ${ }^{4-7}$ However, thin-film growth methods offer unique advantages for the atomic engineering of new HTSc materials through the ability to form artificially layered crystal structures. Moreover, the surfaces of single-crystal substrates provide an "atomic template" that can be used to stabilize epitaxial films in metastable crystal structures. Advances in the understanding of epitaxial thin-film growth of the cuprates have heightened interest in the possibility of creating artificially layered materials. ${ }^{8-}$ 10 The cuprate superconductors are ideal candidates to work on, because their crystal structures are composed of chemically distinct layer modules, most important of which is the square $\mathrm{CuO}_{2}$ layer. The ability to engineer HTSc materials at the atomic level would enable not only the potential development of new phases, but also allow chemically probing of these materials by site-selective substitutions.

An important development in forming novel HTSc structures by artificially-layered epitaxy has been the epitaxial growth of $(\mathrm{Ca}, \mathrm{Sr}) \mathrm{CuO}_{2}$ films in the so-called "infinite layer" structure, ${ }^{11-22}$ This material, which can be considered the parent compound of all of the copper oxide superconductors, has a relatively simple, layered structure consisting of $\mathrm{CuO}_{2}$ planes separated by planes of alkaline earth elements. ${ }^{23}$ Indeed, the infinite-layer structure can be viewed as a fundamental building unit of all of the HTSc cuprates. Bulk synthesis of $(\mathrm{Ca}, \mathrm{Sr}) \mathrm{CuO}_{2}$ with the tetragonal, infinite layer structure generally requires the use of high pressure and high temperature bulk processing techniques. ${ }^{24-29}$ However, recent experiments show that this metastable compound can be epitaxially stabilized at less than atmospheric pressure, resulting in the growth of tetragonal $(\mathrm{Ca}, \mathrm{Sr}) \mathrm{CuO}_{2}$ single crystal thin films of the infinite layer defect perovskite structure by pulsed-laser deposition (PLD) over a wide range of growth conditions. $11-22$

In this paper, we describe the growth and properties of infinite layer $(\mathrm{Ca}, \mathrm{Sr}) \mathrm{CuO}_{2} /(\mathrm{Ba}, \mathrm{Ca}, \mathrm{Sr}) \mathrm{CuO}_{2}$ superlattices using pulsed-laser deposition. By sequentially depositing from different $(\mathrm{Ba}, \mathrm{Ca}, \mathrm{Sr}) \mathrm{CuO}_{2}$ ablation targets in a PLD system, artificially-layered crystalline materials were constructed in which the layering sequence was controlled on nearly the atomiclayer scale. We show that unit-cell control of $(\mathrm{Ca}, \mathrm{Sr}) \mathrm{CuO}_{2}$ growth is possible using pulsed-laser deposition over an oxygen pressure regime in which in situ surface analysis techniques, such as reflection high-energy electron diffraction, are not 
possible. X-ray diffraction peaks attributed to the superlattice structures are observed, even for $\mathrm{SrCuO}_{2} /(\mathrm{Ca}, \mathrm{Sr}) \mathrm{CuO}_{2}$ superlattice structures with $\mathrm{SrCuO}_{2}$ and $(\mathrm{Ca}, \mathrm{Sr}) \mathrm{CuO}_{2}$ layer thicknesses of a single unit cell $(\sim 3.4 \AA)$. The $\mathrm{x}$-ray diffraction data also reveal finite-thickness oscillations in the $x$-ray intensity, which is indicative of films with extremely flat surfaces. The growth of superlattice structures by PLD is made possible, in large part, by this surface flatness.

Transport measurements indicate that the $\mathrm{SrCuO}_{2} /(\mathrm{Ca}, \mathrm{Sr}) \mathrm{CuO} 2$ superiattices are insulating as are the component materials. However, we find that $(\mathrm{Ca}, \mathrm{Sr}) \mathrm{CuO}_{2} / \mathrm{BaCuO}_{2}$ superlattice structures are hole-doped superconductors with a superconducting transition temperature as high as $70 \mathrm{~K}$. The $\mathrm{BaCuO}_{2}$ layers are epitaxially stabilized in the infinite layer structure, and form the integral building block for superconductivity in these superlattice compounds. Note that $\mathrm{BaCuO}_{2}$ normally does not form the infinite layer structure, even by high-pressure synthesis techniques. We have analyzed the dc transport properties of various $(\mathrm{Ca}, \mathrm{Sr}) \mathrm{CuO}_{2} / \mathrm{BaCuO}_{2}$ superlattice structures grown by PLD. We find that the $\mathrm{BaCuO}_{2}$ layers must be at least two-unit cells thick in order for superconductivity to be observed, with $T_{c}$ decreasing as the $(\mathrm{Ca}, \mathrm{Sr}) \mathrm{CuO} 2$ layer thickness is increased for structures with two-unit cell thick $\mathrm{BaCuO}_{2}$ layers. In contrast, $\mathrm{SrCuO}_{2} / \mathrm{BaCuO}_{2}$ structures with relatively thick $\mathrm{BaCuO}_{2}$ layers superconduct at $T_{C} \sim 70 \mathrm{~K}$ independent of $\mathrm{SrCuO}_{2}$ layer thickness. These results suggest that the superconducting transition is primarily associated with the $\mathrm{BaCuO}_{2}$ layers. In addition, we find that the normalized resistances within the superconducting transition region for these structures collapse to a universal resistance curve consistent with the Ginzburg-Landau Coulomb gas model for $2 \mathrm{D}$ vortex fluctuations. ${ }^{30}$ This implies that these superlattices, while structurally similar to several well-characterized HTSc phases, are more 2D-like. Little or no coupling appears to occur across the $(\mathrm{Ca}, \mathrm{Sr}) \mathrm{CuO}_{2}$ layers resulting in the 2-D superconducting nature of these superiattice structures. While effectively decoupling the $\mathrm{BaCuO}_{2}$ layers, the $(\mathrm{Ca}, \mathrm{Sr}) \mathrm{CuO}_{2}$ layers are necessary for epitaxially stabilizing the superconducting $\mathrm{BaCuO}_{2}$ layers in the infinite layer-like structure.

\section{EXPERIMENTAL RESULTS}

The superlattice structures were grown by pulsed-laser deposition on (100) $\mathrm{SrTiO}_{3}$ substrates utilizing polycrystalline $(\mathrm{Ba}, \mathrm{Ca}, \mathrm{Sr}) \mathrm{CuO}_{2}$ ablation targets. 31,32 Polycrystalline, orthorhombic $(\mathrm{Ca}, \mathrm{Sr}) \mathrm{CuO}_{2}$ and cubic $\mathrm{BaCuO}_{2}$ ablation targets were mounted in a multi-target carousel. The $(\mathrm{Ca}, \mathrm{Sr}) \mathrm{CuO}_{2}$ targets were made by solid state reaction of high-purity $\mathrm{SrCO}_{3}$, $\mathrm{CaCO}_{3}$, and $\mathrm{CuO}$ which were pressed and fired at $1025^{\circ} \mathrm{C}$. Powder $\mathrm{x}$-ray diffraction confirmed complete decomposition of the carbonates. The $\mathrm{BaCuO}_{2}$ target was prepared using high-purity $\mathrm{BaCuO}_{2}$ powder. (100) $\mathrm{SrTiO}_{3}$ substrates were cleaned with solvents prior to being mounted with silver paint on the substrate heater. The $\mathrm{KrF}$ excimer laser ablation beam was focused to a $1 \mathrm{~cm}$ horizontal line and vertically scanned over the rotating targets to improve film thickness uniformity. The focused laser energy density was approximately $2 \mathrm{~J} / \mathrm{cm}^{2}$, and the substrates, heated to $500-600^{\circ} \mathrm{C}$, were placed $10 \mathrm{~cm}$ from the ablation targets. Film growth was carried out in 50-200 mTorr of oxygen. The structure and epitaxy of the films were investigated by $x$-ray scattering measurements obtained using both two-circle and four-circle diffractometers with monochromated $\mathrm{CuK} \alpha \mathrm{x}$-ray sources. In addition, more sensitive synchrotron $\mathrm{x}$-ray measurements were obtained for one film using beamline X14 at the National Synchrotron Light Source (NSLS) operating with a Si(111) monochromator and a $\mathrm{Ge}(111)$ analyzer set near the $\mathrm{CuK} \alpha$ wavelength. Transport properties were determined using a four-point resistance measurement with a measuring current density of $50 \mathrm{~A} / \mathrm{cm}^{2}$ or less.

\section{L(Ca, $\mathrm{Sr}) \mathrm{CuO}_{2} / \mathrm{SrCuO}_{2}$ Superlattices}

The growth of superlattice structures by PLD requires a well-calibrated and controlled growth rate. Initial estimates of the film thickness per laser shot were obtained by growing single-component $(\mathrm{Ca}, \mathrm{Sr}) \mathrm{CuO}_{2}$ films and measuring their thickness. However, for superlattice growth, the growth rate and/or sticking coefficient of each component layer can deviate from the values obtained from single-component film growth. For instance, growth of a single unit cell of $\mathrm{SrCuO}_{2}$ on a $\mathrm{Ca}_{0.8} \mathrm{Sr}_{0.2} \mathrm{CuO}_{2}$ surface involves slightly different surface chemistry than growth on $\mathrm{SrCuO}_{2}$, and can lead to a different growth rate. Thus, the final growth rate calibration was obtained from the superlattice satellite peak locations in the $\mathbf{x}$-ray diffraction data.

For $\mathrm{SrCuO}_{2} /(\mathrm{Ca}, \mathrm{Sr}) \mathrm{CuO}_{2}$ superlattices with the infinite layer crystal structure, the $\mathrm{x}$-ray diffraction data should show the infinite layer (001) and (002) peaks, along with superlattice satellite peaks due to the additional chemical modulation from the superlattice structure. The nomenclature used to describe the nominal superlattice structures is $M \times N$, where $M$ is the number of unit cells of the first component, and $\mathrm{N}$ is the number of unit cells of the second component. Figure 1 shows the $\mathrm{x}$-ray diffraction pattern, obtained using a rotating anode $\mathrm{x}$-ray source, for a $2 \mathrm{xl} \mathrm{SrCuO}_{2} / \mathrm{Ca} 0.8 \mathrm{Sr}_{0.2} \mathrm{CuO}_{2}$ superlattice structure with 80 periods grown at $600^{\circ} \mathrm{C}$. The pattern shows peaks due to both the infinite layer crystal structure as well as to the superlattice $\mathrm{Sr} / \mathrm{Ca}$ chemical modulation. Based on the location of the superlattice peaks, the superlattice chemical periodicity is $9.28 \AA$. The fundamental peaks yield an average lattice parameter of $c \sim 3.38 \AA$. A rocking curve through 


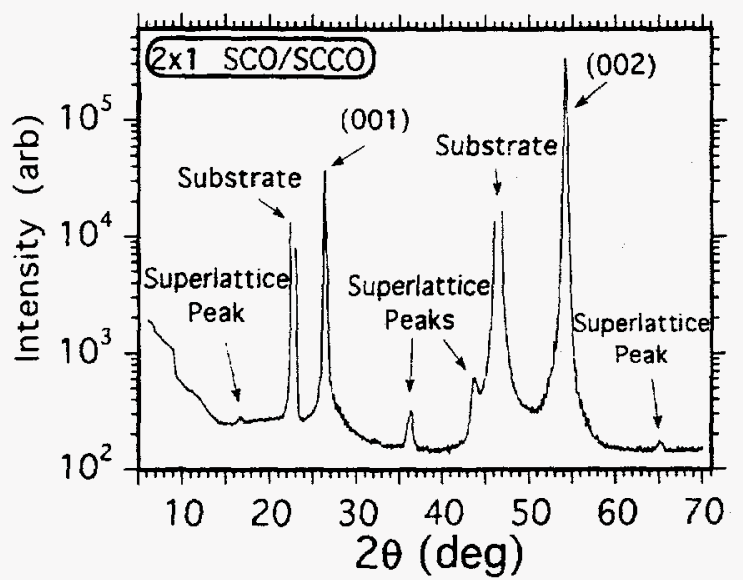

Fig. 1 X-ray diffraction ( $\mathrm{Cu} \mathrm{K} \propto$ radiation) data for a $2 \times 1$ $\mathrm{SrCuO}_{2} / \mathrm{Sr}_{0.2} \mathrm{Ca}_{0.8} \mathrm{CuO}_{2}$ ( $\left.\mathrm{SCO} / \mathrm{SCCO}\right)$ superlattice showing diffraction peaks due to the $\mathrm{Sr} / \mathrm{Ca}$ chemical modulation of the superlattice thin-film structure. From the superlattice peak locations, the superlattice period is $9.28 \AA$.

intensity and width, the $2 \times 2,2 \times 1$, and $1 \times 1 \mathrm{SrCuO}_{2} / \mathrm{Ca} 0.8 \mathrm{Sr}_{0.2} \mathrm{CuO}_{2}$ superlattice structures grown at $500^{\circ} \mathrm{C}$ had superlattice peaks significantly lower in intensity and broader than for similar structures grown at $600^{\circ} \mathrm{C}$. This suggests that the growing surface is significantly smoother at $600^{\circ} \mathrm{C}$ than at $500^{\circ} \mathrm{C}$ due to increased surface diffusion. In addition, this result indicates that bulk interdiffusion is not a significant factor at temperatures up to $600^{\circ} \mathrm{C}$, as interdiffusion of the layers would tend to make the diffraction peaks broader and lower in intensity at the higher temperature.

It is interesting that superlattice structures with component layer thicknesses as small as $3.3 \AA$ can be obtained with a relatively simple thin-film growth system which has no in situ surface analysis capability. This result implies that the growing surface of the infinite layer films must be quite smooth, on a near-atomic scale. A direct measure of this surface smoothness is given in the $\mathrm{x}$-ray diffraction pattern of the $1 \times 1 \mathrm{SrCuO}_{2} / \mathrm{Ca}_{0.8} \mathrm{Sr}_{0.2} \mathrm{CuO}_{2}$ superlattice.

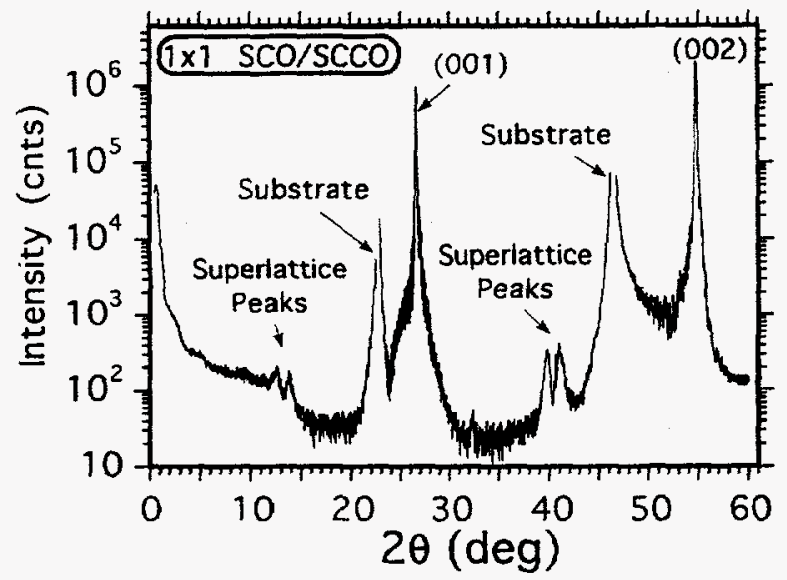

Fig. 2 X-ray diffraction data for a $1 \times 1$ $\mathrm{SrCuO}_{2} / \mathrm{Sr}_{0.2} \mathrm{Ca}_{0.8} \mathrm{CuO}_{2}$ ( $\left.\mathrm{SCO} / \mathrm{SCCO}\right)$ superlattice showing diffraction peaks due to the $\mathrm{Sr} / \mathrm{Ca}$ chemical modulation of the superiattice thin-film structure. The superlattice peaks are split due to the fact that the chemical periodicity is slightly incommensurate with the infinite layer structural periodicity. From the superlattice peak locations, the superlattice period is $7.0 \AA$.

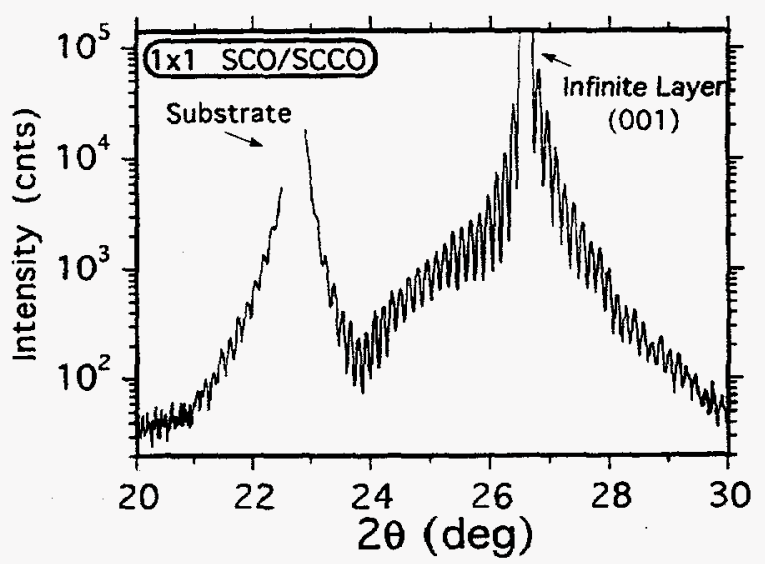

Fig. $3 \mathrm{X}$-ray diffraction data for a $1 \times 1$ $\mathrm{SrCuO}_{2} / \mathrm{Sr}_{0.2} \mathrm{Ca}_{0.8} \mathrm{CuO}_{2}(\mathrm{SCO} / \mathrm{SCCO})$ superiattice about the $(001)$ infinite layer peak showing $x$-ray intensity oscillations due to the finite thickness of the film. The number of resolvable oscillations suggests that the film thickness varies by only $20 \AA$ over a length scale of several thousand angstroms. 
Figure 3 shows an expanded plot about the $(001)$ infinite layer peak, which shows oscillations in the x-ray diffraction intensity due to the finite film thickness. Finite thickness oscillations are observed only if the film surface is flat over a length scale on the order of the coherence length of the x-ray source. For these synchrotron measurements, the coherence length is at least of the order of thousands of angstroms. Over 30 oscillations are present on each side of the (001) peak, giving a fractional variation of film thickness relative to the total film thickness of $1 / 30$, which yields a thickness variation of only $20 \AA$ over thousands of angstroms. ${ }^{33}$ This is on the order of the expected substrate surface roughness, and indicates that these infinite layer films are extremely flat under the growth conditions utilized.

\section{$\underline{2.2 \mathrm{BaCuO}} 2 /(\mathrm{Ca} . \mathrm{Sr}) \mathrm{CuO}_{2}$ Superconducting Superlattices}

While $\mathrm{SrCuO}_{2} /(\mathrm{Ca}, \mathrm{Sr}) \mathrm{CuO}_{2}$ superlattices are insulating, superlattices which contain infinite layer $\mathrm{BaCuO}_{2}$ can be grown which are metallic and superconducting. Before growing $\mathrm{BaCuO}_{2} /(\mathrm{Ca}, \mathrm{Sr}) \mathrm{CuO}_{2}$ superlattice structures, a $9.0 \mathrm{~nm}$ thick $\mathrm{SrCuO}_{2}$ buffer layer was grown to initiate epitaxial growth of the infinite layer structure. The average film growth rates were $0.3 \AA / \mathrm{sec}$ for $(\mathrm{Ca}, \mathrm{Sr}) \mathrm{CuO}_{2}$ and $0.43 \AA / \mathrm{sec}$ for $\mathrm{BaCuO}_{2}$ in the infinite layer structure. The superlattices were grown by alternative ablation from $(\mathrm{Ca}, \mathrm{Sr}) \mathrm{CuO}_{2}$ and $\mathrm{BaCuO}_{2}$ targets for a pre-determined number of laser shots. The $(\mathrm{Ca}, \mathrm{Sr}) \mathrm{CuO} 2$ and $\mathrm{BaCuO}_{2}$ layer thicknesses were controlled by counting laser pulses, with the growth rate per laser shot calibrated from thickness measurements of $(\mathrm{Ca}, \mathrm{Sr}) \mathrm{CuO}_{2}$ films, and from the subsequent x-ray diffraction patterns of $\mathrm{SrCuO}_{2} / \mathrm{BaCuO}_{2}$ superlattice structures. After deposition, the films were cooled at $\sim 80^{\circ} \mathrm{C} / \mathrm{min}$ in $200 \mathrm{mTorr}$ of oxygen, with the pressure increased to 760 Torr at $375^{\circ} \mathrm{C}$.

Superlattice structures, fabricated by alternative ablation of $\mathrm{SrCuO}_{2}$ and $\mathrm{BaCuO}_{2}$ targets, can be nominally described either as $\mathrm{Ba}_{2}+\mathrm{mSr}_{n-1} \mathrm{Cu}_{n+m+1} \mathrm{O}_{2}(\mathrm{~m}+n)+2+\mathrm{d}$ or as $\mathrm{M} \mathrm{x} \mathrm{N} \mathrm{SrCuO} 2 / \mathrm{BaCuO}_{2}$ superlattices, where $M$ and $N$ are the number

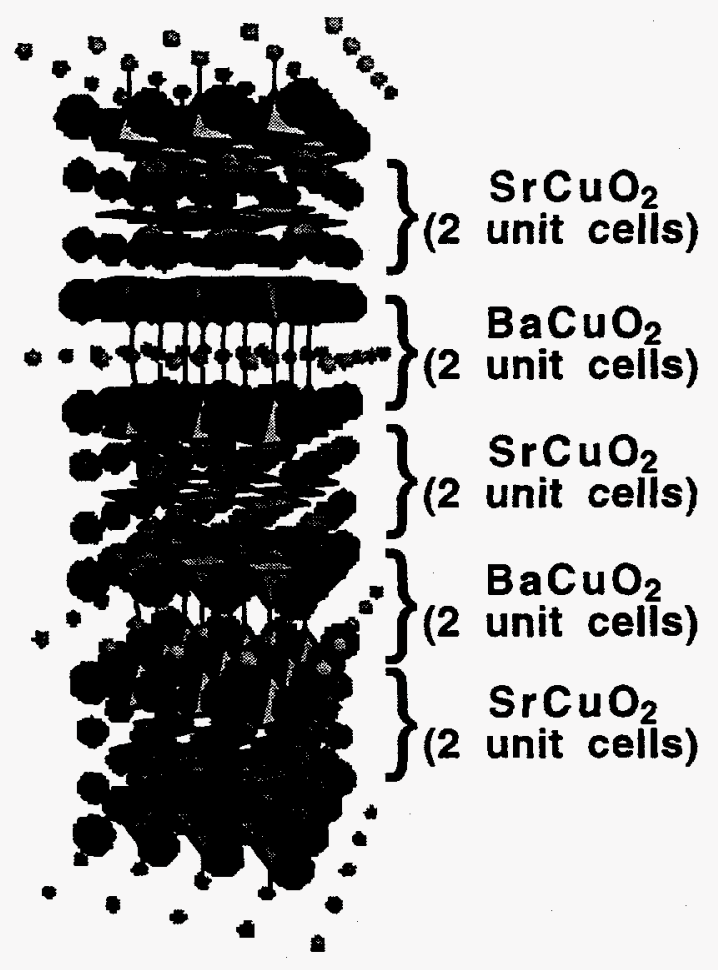

Fig. 4 Structural model of a $2 \times 2 \quad \mathrm{SrCuO}_{2} / \mathrm{BaCuO}_{2}$ superlattice compound, also designated as $\mathrm{Ba}_{2} \mathrm{Sr}_{2} \mathrm{Cu}_{4} \mathrm{O}_{8}+\mathrm{d}$. The $\mathrm{Ba}, \mathrm{Sr}$, and $\mathrm{Cu}$ atoms are represented by the large, medium, and small spheres, respectively. The $\mathrm{CuO}_{4}$ and $\mathrm{CuO}_{5}$ units are shown as shaded polyhedra. of infinite layer $\mathrm{SrCuO}_{2}$ and $\mathrm{BaCuO}_{2}$ unit cells, respectively, per superlattice period. A schematic of a $2 \times 2$ $\mathrm{BaCuO}_{2} / \mathrm{SrCuO}_{2}$ superlattice is shown in Fig 4. The accurate formation of any artificially-layered phase depends on the precision with which growth of the constituent $\mathrm{BaCuO}_{2}$ and $\mathrm{SrCuO}_{2}$ layers can be controlled. X-ray diffraction patterns give a direct measure of the accuracy of the artificially-layered growth scheme in producing the intended structure. X-ray diffraction patterns for the $\mathrm{Ba}_{2} \mathrm{Sr}_{n-1} \mathrm{Cu}_{n+1} \mathrm{O}_{2 n+2+\mathrm{d}}$ films with $n=2,3$, and 4 are shown in Fig. 5, along with corresponding schematics of their ideal atomic arrangements. The solid arrows indicate diffraction peaks from the artificially-layered compounds, while the asterisks designate peaks from the $\mathrm{SrCuO}_{2}$ buffer layer. The vertical dashed lines show the expected locations of the $(00 \ell)$ peaks for ideal artificially-layered structures. The diffraction patterns clearly indicate the presence of mulitlayer modulation along the c-axis. While the diffraction peaks are close to the ideal $(00 \ell)$ locations, some of the peak intensities are weaker than that predicted from structure calculations with slight deviations or splitting of some of the peaks about the expected peak locations. The most consistent interpretation of these diffraction patterns is to view the peaks as originating either from the structural modulation or from the superlattice chemical modulation. The structural modulation arises from the crystallinity of the compound. It represents, for instance, the average cation spacing along the $\mathrm{c}$-axis (the growth direction), with some structure peaks present even with no $\mathrm{Ba} / \mathrm{Sr}$ chemical modulation. For instance, the (003) and (006) peaks for $\mathrm{Ba}_{2} \mathrm{SrCu}_{3} \mathrm{O}_{6+\mathrm{d}}$ would be present for an infinite layer alloy film with no $\mathrm{Ba} / \mathrm{Sr}$ ordering along the c-axis. Only as $\mathrm{Ba} / \mathrm{Sr}$ ordering is realized are other $(00 \ell)$ structure peaks expected. If the $\mathrm{Ba} / \mathrm{Sr}$ chemical modulation is slightly incommensurate 

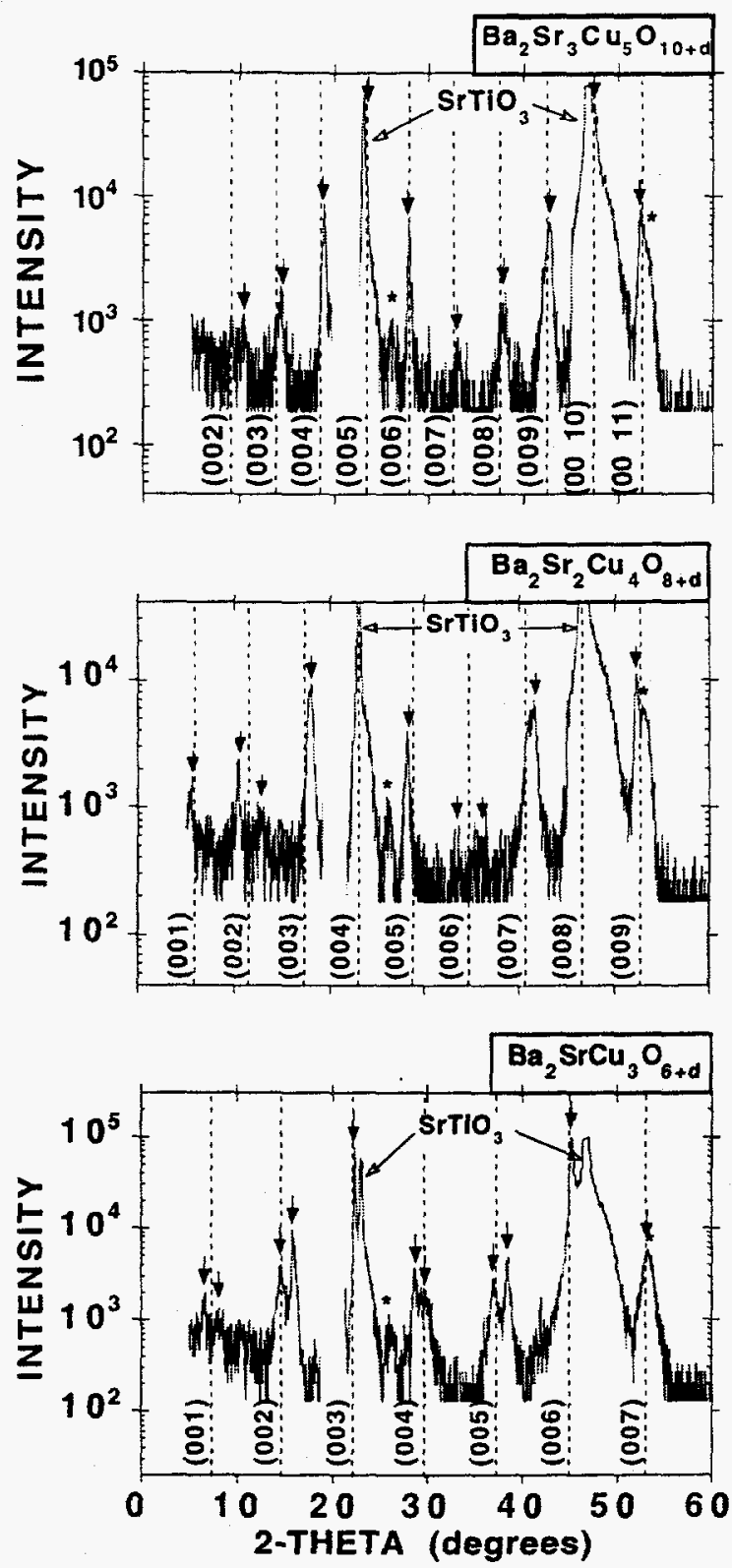
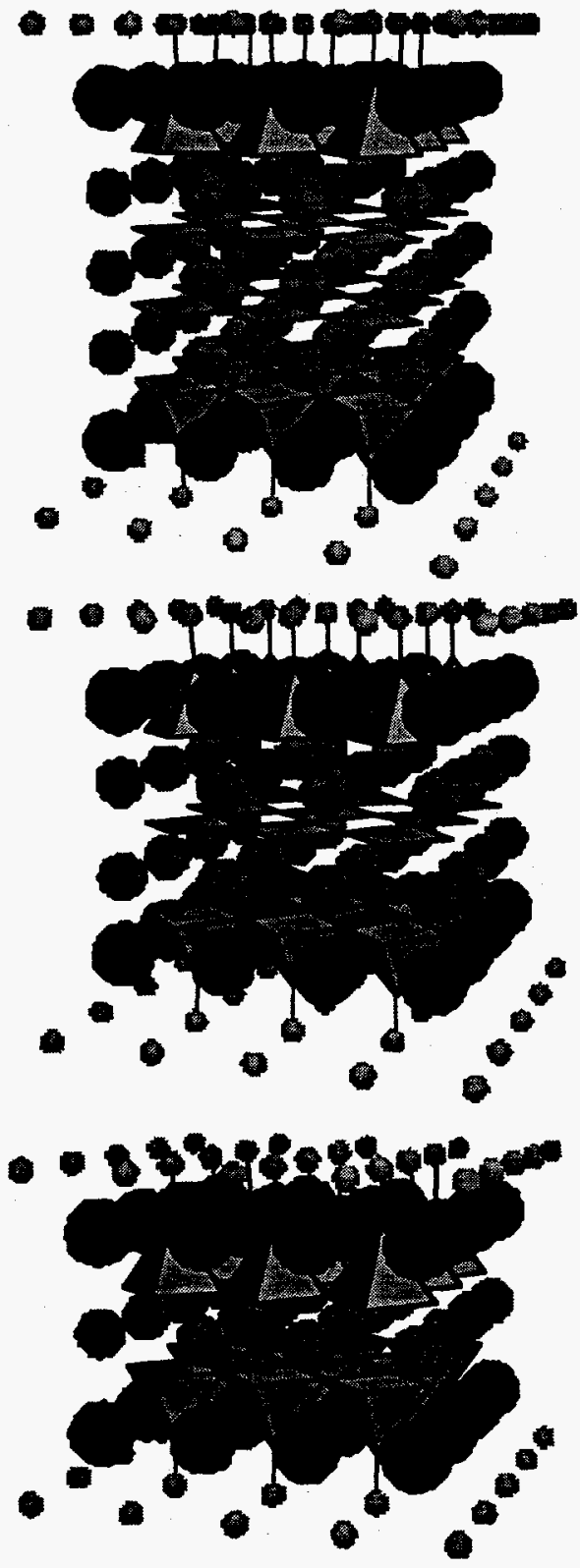

Fig. $5 \mathrm{X}$-ray diffraction patterns ( $\mathrm{Cu} \mathrm{K} \propto$ radiation) and structural models for the $n=2,3$, and 4 members of the $\mathrm{Ba}_{2} \mathrm{Sr}_{n-1} \mathrm{Cu}_{n+1} \mathrm{O}_{2 n+2+d}$ series. The dashed lines indicate the nominal locations of the $(00 \mathrm{l})$ peaks, while the solid arrows indicate diffraction peaks due to the artificially-layered structures. In the models, the $\mathrm{Ba}, \mathrm{Sr}$, and $\mathrm{Cu}$ atoms are represented by the large, medium, and small spheres, respectively, and the $\mathrm{CuO}_{4}$ and $\mathrm{CuO}_{5}$ units as shaded polyhedra.

with the structural modulation, superlattice satellite peaks will be present on either side of strong structural peaks at positions which deviate from the ideal $(00 l)$ locations. Peaks from the structural and chemical periodicities converge if the deposition process yields exactly integral numbers of $\mathrm{SrCuO}_{2}$ and $\mathrm{BaCuO}_{2}$ infinite layer unit cells per multilayer period. The deviations observed in the peak locations indicate that the chemical modulation is slightly incommensurate with the structural modulation for all three structures considered in Fig. 5. The fact that the peak intensities are somewhat weaker than expected indicates the presence of $\mathrm{Ba} / \mathrm{Sr}$ disorder. Since these thin films were formed as artificially-layered superlattices by sequentially depositing $\mathrm{SrCuO}_{2}$ and $\mathrm{BaCuO}_{2}$ layers, it is reasonable to assume that much of this disorder originates from substrate surface roughness and slight inaccuracies in the deposition rates. The $\mathrm{x}$-ray diffraction patterns give c-axis lattice 


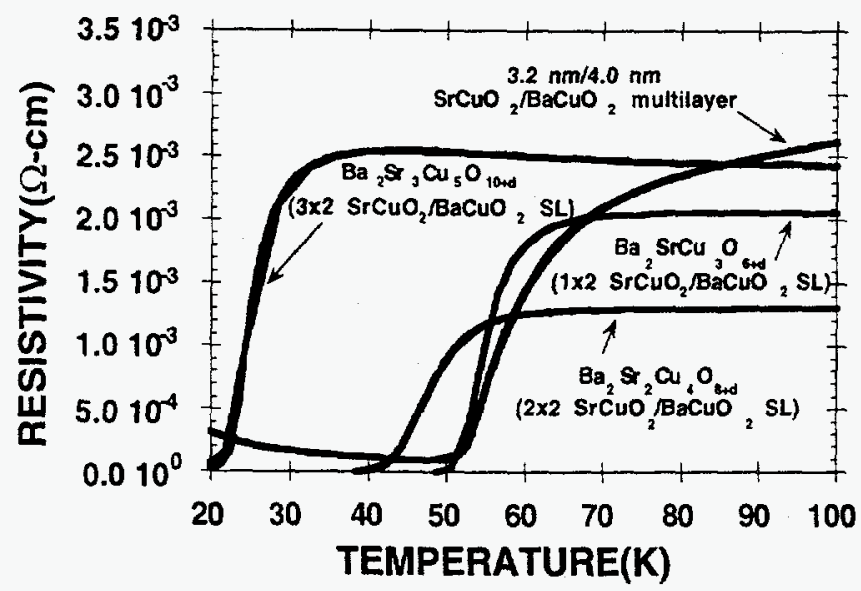

Fig. 6 Resistivity plotted as a function of temperature for the $n=2,3$, and 4 members of the $\quad \mathrm{Ba}_{2} \mathrm{Sr}_{n-}$ ${ }_{1} \mathrm{Cu}_{n+1} \mathrm{O}_{2 n+2+\mathrm{d}}$ series. Also shown in the resistivity of a $3.2 \mathrm{~nm} / 4.0 \mathrm{~nm} \mathrm{SrCuO} 2 / \mathrm{BaCuO}_{2}$ multilayer.

$\mathrm{Cu}$ coordination. The schematics of the $\mathrm{Ba}_{2} \mathrm{Sr}_{1-n} \mathrm{Cu}_{1+n} \mathrm{O}_{2 n+2+d}$ structures shown in Figs. 4 and 5 assume this to be true It is not clear, however, whether oxygen on the Ba planes resides there at the expense of oxygen on specific Cu planes. Because of this uncertainty, we have designated the materials as $\mathrm{Ba}_{2} \mathrm{Sr}_{n-1} \mathrm{Cu}_{n+1} \mathrm{O}_{2 n+n+d}$ and $\mathrm{Ba}_{4} \mathrm{Sr}_{n-1} \mathrm{Cu}_{n+2} \mathrm{O}_{2 n+6+d}$ which makes no inference as to whether inequivalent $\mathrm{Cu}$ sites are present, although this may occur.

Figure 6 shows the normalized resistance for the $n=2,3$, and 4 members of $\mathrm{Ba}_{2} \mathrm{Sr}_{n-1} \mathrm{Cu}_{n+1} \mathrm{O}_{2 n+2+\mathrm{d}}$ whose $\mathrm{x}$-ray diffraction patterns are shown in Fig. 5. We also observe that, for superlattices with 2 unit cell thick $\mathrm{BaCuO}_{2}$ layers, increasing the $\mathrm{SrCuO}_{2}$ layer thickness decreases $T_{c}$. The room-temperature resistivities are $1-5 \mathrm{~m} \Omega-\mathrm{cm}$. The $n=2$ member has the highest superconducting transition temperature with $T_{c}$ (onset) $=62 \mathrm{~K}$ and $T_{c}(\mathrm{R}=0)=50 \mathrm{~K}$. The $n=3$ member has $T_{c}$ (onset) $=56 \mathrm{~K}, T_{c}(\mathrm{R}=0)=40 \mathrm{~K}$, and the $n=4$ member has $T_{c}$ (onset) $=32 \mathrm{~K}$ and $T_{c}(\mathrm{R}=0)=20 \mathrm{~K} . T_{c}$ (onset) is defined as the temperature at which the resistance is $5 \%$ below its normal state value. This decrease in $T_{c}$ with increasing $\mathrm{SrCuO}_{2}$ layer thickness is analogous to that observed in $\mathrm{YBa}_{2} \mathrm{Cu}_{3} \mathrm{O}_{7} / \mathrm{PrBa}_{2} \mathrm{Cu}_{3} \mathrm{O}_{7}$ superlattices. ${ }^{35}$ In $\mathrm{YBa}_{2} \mathrm{Cu}_{3} \mathrm{O}_{7} / \mathrm{PrBa}_{2} \mathrm{Cu}_{3} \mathrm{O}_{7}$ superlattices, charge transfer appears to occur from the superconducting $\mathrm{YBa}_{2} \mathrm{Cu}_{3} \mathrm{O}_{7}$ layers to the insulating $\mathrm{PrBa}_{2} \mathrm{Cu}_{3} \mathrm{O}_{7}$ layers. 36,37 Similar results for $\mathrm{SrCuO}_{2} / \mathrm{BaCuO}_{2}$ superlattices may reflect a charge transfer from the conducting $\mathrm{BaCuO}_{2}$ layers to the insulating $\mathrm{SrCuO}_{2}$ layers In addition to $\mathrm{Ba}_{2} \mathrm{Sr}_{1-n} \mathrm{Cu}_{n+1} \mathrm{O}_{2 n+2+\mathrm{d}}$, superconductivity is also observed in the series designated as $\mathrm{Ba}_{4} \mathrm{Sr}_{n-1} \mathrm{Cu}_{n+3} \mathrm{O}_{2 n+6+d}$. The resistivity and $\mathrm{x}$-ray diffraction pattern for the $n=3$ member is shown in Fig. 7. From the $x$-ray data, the structural and chemical modulation periodicities are both approximately $23.75 \AA$. These $\mathrm{BaCuO}_{2} / \mathrm{SrCuO}_{2}$ superlattices are quite stable over time if stored in a dry ambient.

In addition to the $n \geq 2$ members, we have attempted to synthesize the $n=1$ member, which would be $\mathrm{BaCuO}_{2}$ in the infinite layer structure. If this material can be stabilized and superconducts, it would be important as the small c-axis lattice constant (4.2 or $8.4 \AA$, depending on the oxygen ordering) should make it less anisotropic than other HTSc materials. Unfortunately, our attempts to grow reasonably thick films of $\mathrm{BaCuO}_{2}$ in the infinite layer structure have thus far been unsuccessful. However, we have stabilized $\sim 40 \AA$ thick $\mathrm{BaCuO}_{2}$ layers in the infinite layer structure within $32 \AA / 40 \AA$ $\mathrm{SrCuO}_{2} / \mathrm{BaCuO}_{2}$ multilayers. The resistivity for this structure also is shown in Fig. 7. This film has a strongly metallic resistivity with a superconducting onset near $70 \mathrm{~K}$ that we attribute to the $\mathrm{BaCuO}_{2}$ layer. The non-zero resistivity observed for $\mathrm{T}<50 \mathrm{~K}$ is due to the electrically insulating $32 \AA$-thick $\mathrm{SrCuO}_{2}$ cap layer that was grown to protect the $\mathrm{BaCuO}_{2}$ layers from degradation. Significant positive magnetoresistance is observed for $T \leq 70 \mathrm{~K}$, which is consistent with superconductivity. DC magnetometry revealed the presence of quasi-static persistent currents with a magnetization that was hysteretic in low magnetic fields. From the magnitude of the hysteresis for increasing versus decreasing field history, we estimate, based on the Bean critical state model, 38 that the circulating critical current density is $\sim 2 \times 10^{4} \mathrm{~A} / \mathrm{cm}^{2}$ at $5 \mathrm{~K}$. These classical superconductive features document the fact that this multilayer structure superconducts over large areas. The magnetic signal disappeared near $36 \mathrm{~K}$, somewhat below the $R=0$ point, due to the stringent criterion that there be well connected macroscopic paths for circulating currents. 

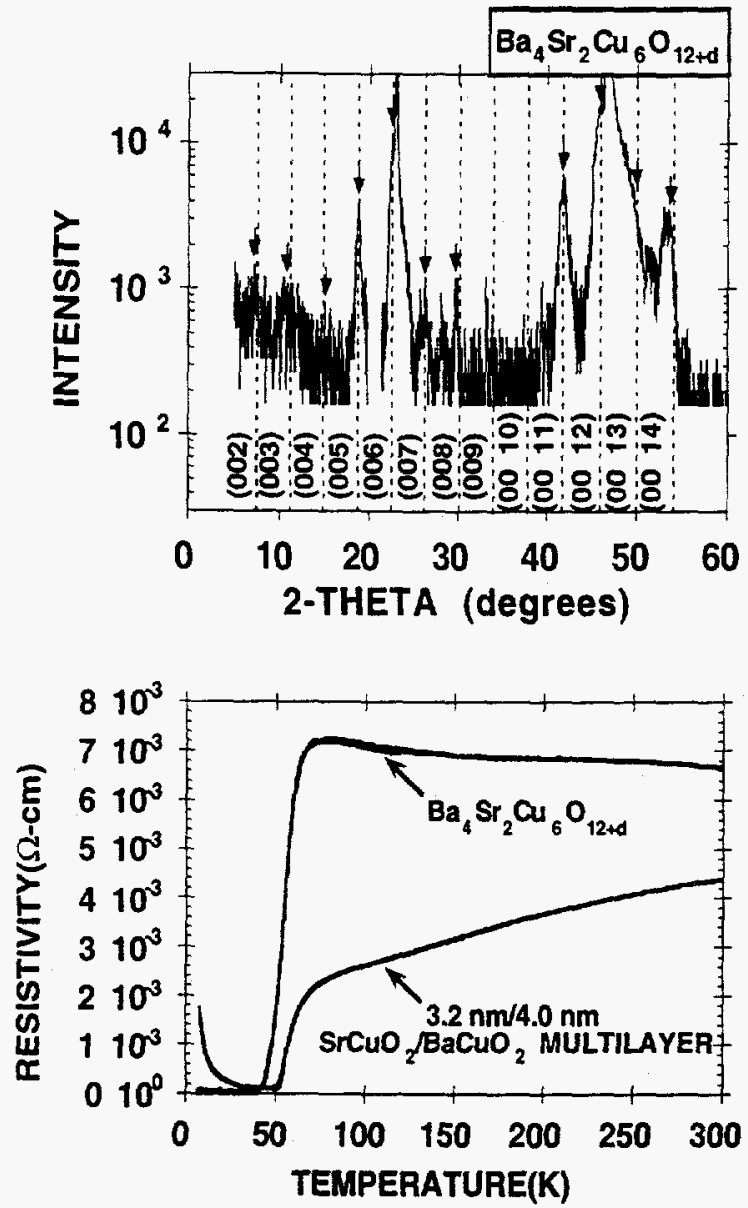

Fig. $7 \mathrm{X}$-ray diffraction pattern and resistivity for the $n=3$ member of the $\mathrm{Ba}_{4} \mathrm{Sr}_{n-1} \mathrm{Cu}_{n+3} \mathrm{O}_{2 n+6+d}$ series. Also shown is the resistivity for the $3.2 \mathrm{~nm} / 4.0 \mathrm{~nm}$ $\mathrm{SrCuO}_{2} / \mathrm{BaCuO}_{2}$ multilayer structure.

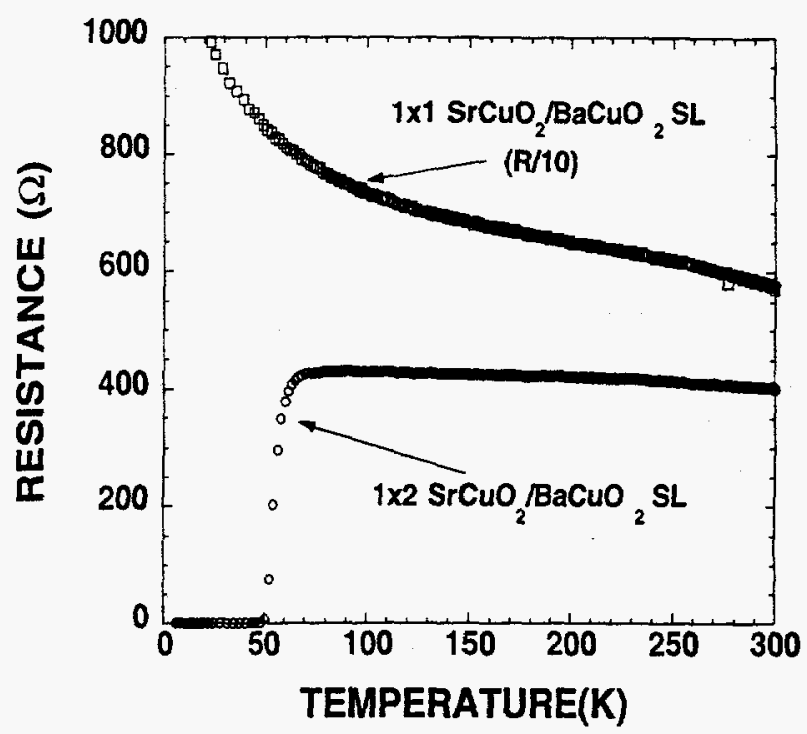

Fig. 8. Resistance plotted as a function of temperature for 1 $\times 1$ and $1 \times 2 \mathrm{SrCuO}_{2} / \mathrm{BaCuO}_{2}$ superlattices showing the dependence of superconductivity on a minimal $\mathrm{BaCuO}_{2}$ layer thickness of two-unit cells.

The $\mathrm{n}=1$ member of theBa $\mathrm{Sr}_{n-1} \mathrm{Cu}_{n+1} \mathrm{O}_{2 n+2+\mathrm{d}}$ series apparently has a value of $T_{\mathcal{C}}$ which is as high or higher than the $n>1$ members. This behavoir differs from that observed for optimally doped HTSc materials, in which $T_{c}$ increases as $\mathrm{n}$ increases. One possible explanation is that these $\mathrm{Ba}_{2} \mathrm{Sr}_{n-1} \mathrm{Cu}_{n+1} \mathrm{O}_{2 n+2+d}$ films are not optimally doped, with an increase in $T_{c}$ possible with an increase or reduction in the hole carrier density. Another possibility is that the use of $\mathrm{Sr}$ to separate the $\mathrm{CuO}_{2}$ planes inhibits the transfer of charge from the $\mathrm{Ba}_{2} \mathrm{Cu}_{2} \mathrm{O}_{4}$ layer into the $\mathrm{SrCuO}_{2}$ layers. This latter scenario would mean that the superconducting transitions observed for all of these structures is due primarily to the $\mathrm{Ba}_{2} \mathrm{Cu}_{2} \mathrm{O}_{4}$ layers, with little coupling in the $\mathrm{CuO}_{2}$ planes adjacent to the $\mathrm{Sr}$ atoms. In fact, this interpretation is somewhat consistent with the observed behavior for $\mathrm{YBa}_{2} \mathrm{Cu}_{3} \mathrm{O}_{7} / \mathrm{PrBa}_{2} \mathrm{Cu}_{3} \mathrm{O}_{7}$ superlattices, where $\mathrm{T}_{c}$ decreases as the nonsuperconducting $\mathrm{PrBa}_{2} \mathrm{Cu}_{3} \mathrm{O}_{7}$ layer thickness decreases.

In $\mathrm{SrCuO}_{2} / \mathrm{BaCuO}_{2}$ superlattices, superconductivity is observed only for structures in which the $\mathrm{BaCuO}_{2}$ layers are a minimum of 2 unit cells thick, while $\mathrm{Ca}_{0.9} \mathrm{Sr}_{0.1} \mathrm{CuO}_{2} / \mathrm{BaCuO}_{2}$ structures require at least 3 unit cell thick $\mathrm{BaCuO}_{2}$ layers. Figure 8 shows the resistance for $1 \times 1$ and $1 \times 2 \mathrm{SrCuO}_{2} / \mathrm{BaCuO}_{2}$ superlattice structures. $\mathrm{X}$-ray diffraction indicates that these structures are epitaxial with the infinite layer structure, although precise determination of the location for the oxygen atoms is not possible. It is probable that some oxygen is in the $\mathrm{Ba}$ layer, providing apical oxygen above $\mathrm{CuO}_{2}$ planes. As shown in Fig. 8, superconductivity is observed in the $1 \times 2 \mathrm{SrCuO}_{2} / \mathrm{BaCuO}_{2}$ superlattice, but not in the $1 \times 1$ structure. Structures with $\mathrm{BaCuO}_{2}$ layer thickness greater than 2 unit cells superconduct at temperatures approaching $70 \mathrm{~K}$, depending on the $\mathrm{SrCuO}_{2}$ layer thickness. Structures with less than 2 unit cells thick $\mathrm{BaCuO}_{2}$ layers are hole-doped, but do not superconduct. Note that the 2 unit cell thick $\mathrm{BaCuO}_{2}$ layers in $\mathrm{M} \times 2$ superlattices are similar to those found in $\mathrm{YBa}_{2} \mathrm{Cu}_{3} \mathrm{O}_{7}$, which has the $\mathrm{Cu}-\mathrm{O}$ chain layer between two Ba-O layers. From a cation point of view, a $1 \times 2$ $\mathrm{SrCuO}_{2} / \mathrm{BaCuO}_{2}$ superlattice is essentially the $\mathrm{YBa}_{2} \mathrm{Cu}_{3} \mathrm{O}_{7}$ structure with $\mathrm{Y}$ replaced with $\mathrm{Sr}$. These results suggest that the superconducting transition in $\mathrm{SrCuO}_{2} / \mathrm{BaCuO}_{2}$ superlattices is primarily associated with the $\mathrm{BaCuO}_{2}$ layers. 


\subsection{Two Dimensional Vortex Fluctuations in $\mathrm{BaCuO}_{2} /(\mathrm{Ca}, \mathrm{Sr}) \mathrm{CuO} 22$ Superlattices}

In order to better understand the superconducting nature of the superlattices, we have analyzed the resistive transitions within the context of superconductivity in two-dimensional structures. In a $2 \mathrm{D}$ superconductor, vortex fluctuations dictate the shape of the resistive transition from the normal state to the superconducting state. ${ }^{30,39}$ At very low temperatures the vortices are bound as vortex-antivortex pairs, due to the logarithmic form of their interaction. As bound pairs, these vortices introduce no dissipation in the zero-current limit. However, as the temperature is increased above the Kosterlitz-Thouless temperature, $T_{K T}$, the system undergoes a $2 \mathrm{D}$ phase transition, as unbinding of some of the vortex-antivortex pairs results in the creation of free vortices and the onset of dissipation. As the temperature is increased, more free vortices are generated and dissipation increases. Halperin and Nelson have developed analytical expressions for the form of the 2D flux flow resistance that are expected to be valid only within the critical region, which lies very near $T_{K T} T^{39-45}$ An alternative approach, which is valid outside the $K T$ critical region, is based on the Ginzburg-Landau Coulomb gas (GLCG) model and the Coulomb gas concept. ${ }^{30,46}$ In this model, 2D vortices are treated as particles of a $2 \mathrm{D}$ Coulomb gas. The superconductor, in the absence of vortices, is assumed to be well described by a Ginzburg-Landau theory. The shape and energy of an isolated vortex are obtained by minimizing the Ginzburg-Landau equations, and the energy of the vortex configuration is estimated by superposition of single Ginzburg-Landau vortices. Vortex fluctuations described by this model are controlled by two effective parameters, an effective dimensionless Coulomb gas temperature variable, $T^{C G}=k_{B} T /\left[2 \pi \rho_{o}(\mathrm{~T})\left(\mathrm{H} / m^{*}\right)^{2}\right]$, and the GinzburgLandau coherence length $\xi(T)$. The GLCG model leads to some rather simple scaling relations that should be valid well outside the critical region and should be universal for all 2D superconductors. In particular, the GLCG model states that any property arising from $2 \mathrm{D}$ vortex fluctuations, when expressed in dimensionless form, should be a universal function of the scaled temperature $T^{C G}$.

The flux flow resistance ratio, $R / R_{n}$, where $R_{n}$ is the normal state resistance, is such a quantity. All $2 \mathrm{D}$ superconductors that are well described by the GLCG model should produce the same $R(T C G) / R_{n}$ curve. For convenience, the scaling variable is chosen to be $X=T^{C G}(T) / T^{C G}\left(T_{K T}\right)$. Fitting the data to the universal curve requires the determination of two parameters, the critical temperature for the vortex $2 \mathrm{D}$ phase transition, $T_{K T}$, and the Ginzburg-Landau temperature, $T_{c o}$. The form of the universal resistance curve has been determined experimentally, using data from several type-II superconducting thin film systems. ${ }^{30}$ Comparison of data for other superconducting films to the universal $R / R_{n}$ curve gives a good indication of their $2 \mathrm{D}$ nature.

Consider the normalized resistance transitions shown in Fig. 9 for several $(\mathrm{Ca}, \mathrm{Sr}) \mathrm{CuO}_{2} / \mathrm{BaCuO}_{2}$ superlattices grown under a variety of conditions. For these samples, the $\mathrm{BaCuO}_{2}$ layer thicknesses remains essentially fixed at two-unit cells, while the composition and thickness of the $(\mathrm{Ca}, \mathrm{Sr}) \mathrm{CuO}_{2}$ layers, along with the temperature and oxygen pressure used in film growth, are varied. Note that $T_{c}$ ranges from 15 to $50 \mathrm{~K}$, depending on the specific superlattice structure and growth conditions. If the transport properties of these superlattice structures are dictated by $2 D$ vortex fluctuations, the GLCG model predicts that the data for each of these structures should collapse onto the universal resistance curve when plotted against the scaled temperature variable. Figure 10 shows the normalized resistance as a function of the scaled temperature variable for the structures described in Fig. 9. For all of the samples over a relatively large temperature range, the resistance data collapse onto the universal curve. Note that the scaling variable $X=T^{C} C G_{(T) / T} C G_{(T K T)}$ can be expressed as $X=T\left(T_{c 0^{-}} T_{K T}\right) /\left(T_{c 0^{-}}\right.$ $T) T_{K T}$, assuming that the Ginzburg-Landau expression for $\rho_{o}(T)=\rho_{o}\left(1-T / T_{c o}\right)$ is valid. The collapse of the data involves determining values for only two parameters, the Ginzburg-Landau transition temperature and the Kosterlitz-Thouless transition temperature. A few samples show small deviations from this universal resistance curve as the temperature approaches $T_{K T}$, perhaps indicating where the dc transport properties are no longer determined solely by two-dimensional vortex fluctuations, but are influenced by specific defects associated with the artificially-layered epitaxial structures. Nevertheless, for a relatively large temperature range, the normalized resistance data for these $(\mathrm{Ca}, \mathrm{Sr}) \mathrm{CuO}_{2} / \mathrm{BaCuO}_{2}$ superlattices agree with the predictions of the GLCG model for 2D vortex fluctuations.

A consistent interpretation of the transport properties for these superlattice structures is that the superconducting transition is primarily associated with the $\mathrm{BaCuO}_{2}$ layers which are decoupled from other $\mathrm{BaCuO}_{2}$ layers by insulating $(\mathrm{Ca}, \mathrm{Sr}) \mathrm{CuO}_{2}$ layers. For superlattices with $\mathrm{BaCuO}_{2}$ layers 2 unit cells thick, $2 \mathrm{D}$ vortex fluctuations dominate the resistive transitions even for superlattice structures with $\mathrm{SrCuO}_{2}$ layer thicknesses of only 1 unit cell. This differs quantitatively from that observed for $\mathrm{YBa}_{2} \mathrm{Cu}_{3} \mathrm{O}_{7} / \mathrm{PrBa}_{2} \mathrm{Cu}_{3} \mathrm{O}_{7}$ superlattices in which $\mathrm{PrBa}_{2} \mathrm{Cu}_{3} \mathrm{O}_{7}$ layers greater than 8 unit cells are necessary to completely decouple ultrathin $\mathrm{YBa}_{2} \mathrm{Cu}_{3} \mathrm{O}_{7}$ layers and to observe $2 \mathrm{D}$, instead of anisotropic $3 \mathrm{D}$, vortex fluctuation behavior. ${ }^{46}(\mathrm{Ca}, \mathrm{Sr}) \mathrm{CuO}_{2}$ layers grown under the conditions considered appear to be effective at decoupling adjacent $\mathrm{BaCuO}_{2}$ layers. The observed maximum $T_{\mathcal{C}} \sim 70 \mathrm{~K}$ for these superlattices appears to be the superconducting transition temperature for the two- unit-cell thick $\mathrm{BaCuO}_{2}$ layer. The $(\mathrm{Ca}, \mathrm{Sr}) \mathrm{CuO}_{2}$ layers, while necessary in epitaxially-stabilizing 


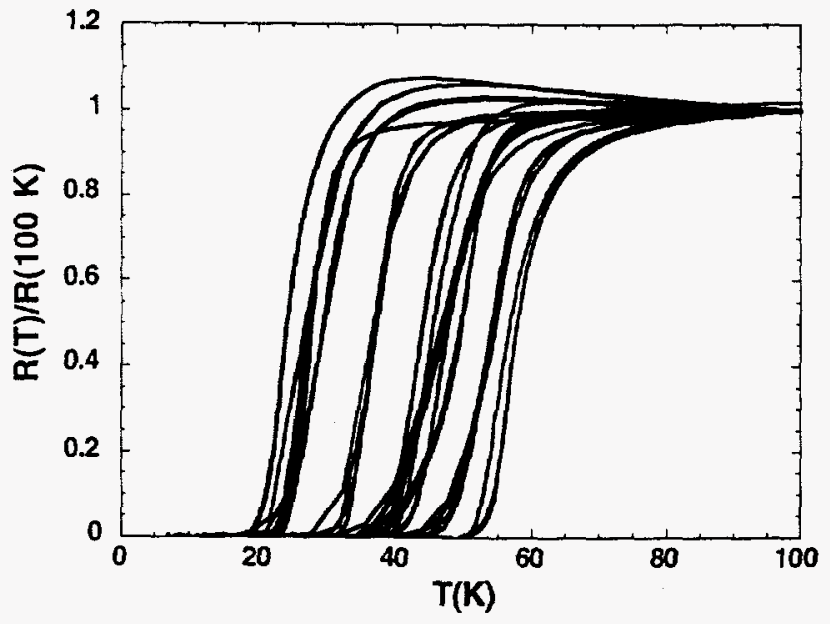

Fig. 9. Normalized resistive transitions for various $1 \times 2,2$ $\times 2$, and $3 \times 2 \quad \mathrm{SrCuO}_{2} / \mathrm{BaCuO}_{2}$, along with $2 \times 2$ $\mathrm{Ca}_{0.1} \mathrm{Sr}_{0.9} \mathrm{CuO}_{2} / \mathrm{BaCuO}_{2}$ and $\mathrm{Ca}_{0.2} \mathrm{Sr}_{0.8} \mathrm{CuO}_{2} / \mathrm{BaCuO}_{2}$ superlattices.

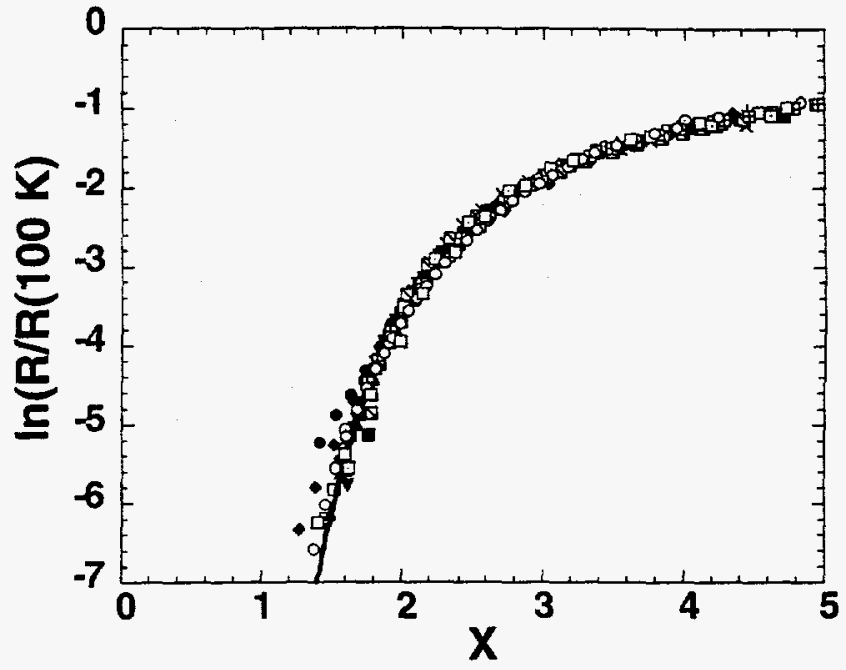

Fig. 10. The normalized resistances plotted as a function of the GLCG scaling variable $\mathrm{X}$ for the superlattice structures considered in Fig. 9.

$\mathrm{BaCuO}_{2}$ in the infinite layer structure, effectively decouples and reduces the carrier density in adjacent $\mathrm{BaCuO}_{2}$ layers. This is consistent with the $T_{c}$ (onset) $\sim 70 \mathrm{~K}$ observed for $\mathrm{SrCuO}_{2} / \mathrm{BaCuO}_{2}$ multilayers in which the layers were relatively thick.

It is interesting to note that, while 1 unit cell thick $(\mathrm{Ca}, \mathrm{Sr}) \mathrm{CuO}_{2}$ layers effectively decouple adjacent $\mathrm{BaCuO}_{2}$ layers in the superiattices, similar $\mathrm{CaCuO}_{2}$ layers found in other $\mathrm{HTSc}$ compounds allow interplane coupling to occur. One possible difference is the presence of $\mathrm{Sr}$ in these superlattices. However, another likely source for this discrepancy lies in the fact that the maximum growth temperature for the superlattices is significantly lower than the optimum temperatures for growth of most HTSc phases. The lower growth temperatures necessary for epitaxially stabilizing $(\mathrm{Ca}, \mathrm{Sr}) \mathrm{CuO}_{2} / \mathrm{BaCuO}_{2}$ superlattices may result in defect formation in the $(\mathrm{Ca}, \mathrm{Sr}) \mathrm{CuO}_{2}$ layers which limits their transport properties.

\section{CONCLUSION}

In conclusion, we have grown $(\mathrm{Ca}, \mathrm{Sr}) \mathrm{CuO}_{2} /(\mathrm{Ba}, \mathrm{Ca}, \mathrm{Sr}) \mathrm{CuO}_{2}$ superlattice structures in the tetragonal, infinite layer crystal structure using conventional pulsed-laser deposition. X-ray diffraction reveals peaks due to the superlattice chemical modulation, even for structures with $\mathrm{SrCuO}_{2}$ and $(\mathrm{Ca}, \mathrm{Sr}) \mathrm{CuO}_{2}$ layers as thin as a single infinite layer unit cell $(\sim 3.4 \AA)$. The $x$-ray diffraction data also show intensity oscillations due to the finite thickness of the film, indicating extremely flat film surfaces with thickness variations of only $20 \AA$ over a length scale of several thousand angstroms. Superconductivity is observed in $\mathrm{BaCuO}_{2} /(\mathrm{Ca}, \mathrm{Sr}) \mathrm{CuO}_{2}$ superlattices with $\mathrm{T}_{\mathrm{c}}$ (onset) $\sim 70 \mathrm{~K}$. We find that the $\mathrm{BaCuO}_{2}$ layers must be at least 2 unit cells thick in order for superconductivity to be observed, and that the superconducting transition is primarily associated with the $\mathrm{BaCuO}_{2}$ layers. In addition, the GLCG model for 2D vortex fluctuations gives a consistent description of the broadening of the superconducting transitions that is observed in artificially-layered $(\mathrm{Ca}, \mathrm{Sr}) \mathrm{CuO}_{2} / \mathrm{BaCuO}_{2}$ superlattices. The collapse of the $R(T)$ data to a single universal curve suggest that 2D vortex fluctuations strongly influence the low temperature transport properties of these superlattice structures making them attractive systems for studying 2-D superconductivity. The ability to grow infinite layer superlattices with $(\mathrm{Ba}, \mathrm{Ca}, \mathrm{Sr}) \mathrm{CuO}_{2}$ layers as thin as a single unit cell using conventional pulsed-laser deposition greatly expands the possibility of atomic engineering of new, artificially-layered high-temperature superconducting phases via layer-by-layer growth schemes.

\section{ACKNOWLEDGMENTS}

This research was sponsored by the Division of Materials Sciences, Oak Ridge National Laboratory, managed by Lockheed Martin Energy Research Corp. for the U.S. Department of Energy under contract DE-AC05-96OR22464. Part of this research was performed at the ORNL PRT Beamline X-14 at the National Synchrotron Light Source, Brookhaven National Laboratory. 


\section{REFERENCES}

1. J. G. Bednorz and K. A. Muller, "Possible high $\mathrm{T}_{\mathrm{c}}$ superconductivity in the Ba-La-Cu-O system," $Z$. Phys. $B$, Cond. Matter, Vol. 64, pp. 189-193, 1986.

2. T. A. Vanderah, Chemistry of Superconductor Materials, Noyes Publications, Park Ridge, N. J., 1992

3. A. Schilling, M. Cantoni, J. D. Guo, H. R. Ott, "Superconductivity above $130 \mathrm{~K}$ in the Hg-Ba-Ca-Cu-O system," Nature, Vol. 363, pp. 56-58, 1993.

4. H. Ihara, K. Tokiwa, H. Ozawa, M. Hirabayashi, A. Negishi, H. Matuhata, and Y. S. Song, "New high-T $\mathrm{T}_{\mathrm{c}}$ superconductor family of $\mathrm{Cu}$-based $\mathrm{Cu}_{1-\mathrm{x}} \mathrm{Ba}_{2} \mathrm{Ca}_{\mathrm{n}-1} \mathrm{Cu}_{\mathrm{n}} \mathrm{O}_{2 \mathrm{n}+4-\mathrm{d}}$ with $\mathrm{T}_{\mathrm{c}}>116 \mathrm{~K}$," Jpn. J. Appl. Phys., Vol. 33, pp. L503L506, 1994.

5. C. -Q. Jin, S. Adachi, X. -J. Wu, H. Yamauchi, S. Tanaka, "117 K superconductivity in the Ba-Ca-Cu-O system," Physica C, Vol. 223, pp. 238-242, 1994.

6. M. A. Alario-Franco, C. Chaillout, J. J. Capponi, J. -L. Thoulence, B. Souletie, "A new HTSC family: The copper analogs of the single-layer $\mathrm{Hg}$ or Tl copper oxide superconductors," Physica C, Vol. 222, pp. 52-56, 1994.

7. Z. Hiroi, M. Takano, M. Azuma, Y. Takeda, "A new family of copper oxide superconductors $\mathrm{Sr}_{n+1} \mathrm{Cu}_{\mathrm{n}} \mathrm{O}_{2 \mathrm{n}+1+\mathrm{d}}$ stabilized at high pressure," Nature, Vol. 364, pp. 315-317, 1993.

8. J. N. Eckstein, I. Bozovic, K. E. von Dessonneck, D. G. Schlom, J. S. Harris, Jr., and S. M. Baumann, "Atomicaily layered heteroepitaxial growth of single-crystal films of superconducting $\mathrm{Bi}_{2} \mathrm{Sr}_{2} \mathrm{Ca}_{2} \mathrm{Cu}_{3} \mathrm{O}_{x}, "$ Appl. Phys. Lett., Vol. 57, pp. 931-933, 1990.

9. T. Terashima, Y. Bando, K. Iijima, K. Yamamoto, K. Hirata, K. Hayashi, K. Kamigaki, and H. Terauchi, "Reflection high-energy electron diffraction oscillations during epitaxial growth of high-temperature superconducting oxides," Phys. Rev. Lett., Vol. 65, pp. 2684-2687, 1990.

10. M. Y. Chern, A. Gupta, B. W. Hussey, "Layer-by-layer deposition of $\mathrm{La}_{1.85} \mathrm{Sr}_{0.15} \mathrm{CuO}_{\mathrm{x}}$ films by pulsed laser ablation," Appl. Phys. Lett., Vol. 60, pp. 3045-3047, 1992.

11. M. Kanai, T. Kawai, and S. Kawai, "Atomic layer and unit cell layer growth of $(\mathrm{Ca}, \mathrm{Sr}) \mathrm{CuO}_{2}$ thin film by laser molecular beam epitaxy," Appl. Phys. Lett., Vol. 58, pp. 771-773, 1991.

12. X. Li, M. Kanai, T. Kawai, and S. Kawai, "Epitaxial growth and properties of $\mathrm{Ca}_{1-\mathrm{x}} \mathrm{Sr}_{\mathrm{x}} \mathrm{CuO}_{2}$ thin film ( $\mathrm{x}=0.18$ to 1.0) prepared by co-deposition and atomic layer stacking," Jpn. J. Appl. Phys., Vol. 31, pp. L217-L220, 1992.

13. X. Li, T. Kawai, and S. Kawai, "Observation of resistive and magnetic anomalies at 90-180 K in artificially layered $\mathrm{Ca}_{1-\mathrm{x}} \mathrm{Sr}_{\mathrm{x}} \mathrm{CuO}_{2}$ thin films grown by laser molecular beam epitaxy," Jpn. J. Appl. Phys., Vol. 31, pp. L934-L937, 1992.

14. M. Yoshimoto, H. Nagata, J. Gong, H. Ohkubo, and H. Koinuma, "Laser MBE of layered $\left[(\mathrm{AE})^{2+} /\left(\mathrm{CuO}_{2}\right)^{2-}\right]_{\mathrm{n}}$ (AE=Sr or Ba) lattices," Physica $C$ 185-189, pp. 2085-2086, 1991.

15. C. Niu and C. M. Lieber, "Low temperature growth of the infinite layer phase of $\mathrm{SrCuO}_{2}$ by pulsed laser deposition," J. Am. Chem. Soc., Vol. 114, pp. 3570-3571, 1992.

16. C. Niu and C. M. Lieber, "Exploiting laser based methods for low temperature solid-state synthesis: Growth of a series of metastable $\left(\mathrm{Sr}_{1-\mathrm{x}} \mathrm{M}_{\mathrm{x}}\right)_{1-\mathrm{d}} \mathrm{CuO}_{2}$ materials," J. Am. Chem. Soc., Vol. 115, pp. 137-144, 1993.

17. S. Gonda, H. Nagata, M. Kawasaki, M. Yoshimoto, and H. Koinuma, "In situ surface analysis of $\mathrm{SrCuO}_{2}$ heteroepitaxy on $\mathrm{SrTiO}_{3}$ substrate using X-ray photoelectron spectroscopy, Physica C, Vol. 216, pp. 160-164, 1993.

18. K. Kobayashi, Y. Ishihara, S. Matsushima, and G. Okada, "Electrical properties of Y-doped $\mathrm{CaCuO}_{2}$ films prepared by organometallic chemical vapor deposition," Appl. Phys. Lett., Vol. 30, pp. 2868-2870, 1993.

19. Y. Terashima, R. Sato, S. Takeno, S. Nakamura, and T. Miura, "Preparation of $\mathrm{SrCuO}_{\mathrm{X}}$ thin films with the infinite layer structure," Jpn. J. Appl. Phys., Vol. 32, pp. L48-L50, 1993.

20. S. Takeno, S. Nakamura, Y. Terashima, and T. Miura, "A high-resolution electron microscopy study on epitaxial infinite-layer $\mathrm{SrCuO}_{2}$ thin films grown on a $\mathrm{SrTiO}_{3}(100)$ substrate," Physica C, Vol. 206, pp. 75-80, 1993.

21. N. Terada, G. Zouganelis, M. Jo, M. Hirabayashi, K. Kaneko, and H. Ihara, "Crystal and electronic structure of $\mathrm{MCuO}_{2 \pm d}$ thin films," Physica C, Vol. 185-189, pp. 2019-2020, 1991.

22. D. P. Norton, B. C. Chakoumakos, E. C. Jones, D. K. Christen, and D. H. Lowndes, "Anomalous transport and structural properties of $\mathrm{Sr}_{1-\mathrm{x}} \mathrm{CuO}_{2-\mathrm{d}}$ thin films," Physica C, Vol. 217, pp. 146-150, 1993.

23. T. Siegrist, S. M. Zahurak, D. W. Murphy, and R. S. Roth, "The parent structure of the layered high-temperature superconductors," Nature, Vol. 334, pp. 231-232, 1988.

24. M. G. Smith, A. Manthiram, J. Zhou, J. B. Goodenough, and J. J. Markert, "Electron-doped superconductivity at

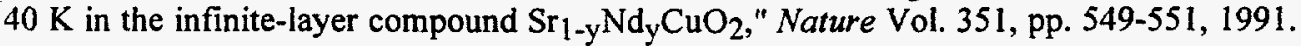

25. G. Er, Y. Miyamoto, F. Kanamaru, and S. Kikkawa, "Supercondcutivity in the infinite-layer compound $\mathrm{Sr}_{1-\mathrm{x}} \mathrm{La}_{\mathrm{x}} \mathrm{CuO}_{2}$ prepared under high pressure," Physica C, Vol. 181, pp. 206-208, 1991.

26. M. Takano, M. Azuma, Z. Hiroi, Y. Bando, and Y. Takeda, "Superconductivity in the Ba-Sr-Cu-O system," Physica C Vol. 176, pp. 441-444, 1991. 
27. Z. Hiroi, M. Takano, M. Azuma, Y. Takeda, and Y. Bando, "A new superconducting cupric oxide found in the Sr-Cu-O system," Physica C Vol. 185-189, pp. 523-534, 1991.

28. M. Azuma, Z. Hiroi, M. Takano, Y. Bando, and Y. Takeda, "Superconductivity at $110 \mathrm{~K}$ in the infinite-layer compound $\left(\mathrm{Sr}_{1-\mathrm{x}} \mathrm{Ca}_{\mathrm{x}}\right)_{1-\mathrm{y}} \mathrm{CuO}_{2}, "$ Nature, Vol. 356, pp. 775-776, 1992.

29. M. Takano, Y. Takeda, H. Okada, M. Miyamoto, and K. Kusaka, "ACuO 2 (A: alkaline earth) crystallizing in a layered structure," Physica C, Vol. 159, pp. 375-378, 1989.

30. P. Minnhagen, "The two-dimensional Coulomb gas, vortex unbinding, and superfluid-superconducting films," Rev. Mod. Phys., Vol. 59, 1001-1067, 1987.

31. D. P. Norton, B. C. Chakoumakos, J. D. Budai, D. H. Lowndes, "Epitaxial growth of single-crystal $\mathrm{Ca}_{1-\mathrm{x}} \mathrm{Sr}_{\mathrm{x}} \mathrm{CuO}_{2}$ thin films by pulsed-laser deposition," Appl. Phys. Lett., Vol. 62, pp. 1679-1681, 1993.

32. D. P. Norton, B. C. Chakoumakos, J. D. Budai, D. H. Lowndes, B. C. Sales, J. R. Thompson, and D. K. Christen, "Superconductivity in $\mathrm{SrCuO}_{2}-\mathrm{BaCuO}_{2}$ superlattices: Formation of artificially layered superconducting materials," Science, Vol. 265, pp. 2074-2077, 1994.

33. O. Nakamura, E. Fullerton, J. Guimpel, and I. Schuller, "High $T_{c}$ thin films with roughness smaller than one unit cell," Appl. Phys. Lett., Vol. 60, pp. 120-122, 1992.

34. S. D. Obertelli, J. R. Cooper, J. L. Tallon, "Systematics in the thermoelectric power of high- $T_{c}$ oxides,"Phys. Rev. $B$, Vol. 46, pp. 14928-14931, 1992.

35. D. P. Norton, D. H. Lowndes, S. J. Penneycook, and J. D. Budai, "Depression and broadening of the superconducting transition in superlattices based on $\mathrm{YBa}_{2} \mathrm{Cu}_{3} \mathrm{O}_{7-\mathrm{d}}$ : Influence of the barrier layers," Phys. Rev. Lett., Vol. 67, pp. 1358-1361, 1991.

36. M. Rasolt, T. Edis, and Z. Tesanovic, "Kosterlitz-Thouless transition and charge redistribution in the superconductivity of YBCO/PBCO superlattices," Phys. Rev. Lett., Vol. 66, pp. 2927-2930, 1991.

37. R. F. Wood, "Spin polarons, hole filling, and high- $\mathrm{T}_{\mathrm{c}}$ superconductivity in $\mathrm{YBa}_{2} \mathrm{Cu}_{3} \mathrm{O}_{7}$ and $\mathrm{PrBa}_{2} \mathrm{Cu}_{3} \mathrm{O}_{7}$ alloys and layered films," Phys. Rev. Lett., Vol. 66, pp. 829-832, 1991.

38. W. A. Fietz and W. W. Webb, "Hysteresis in superconducting alloys - Temperature and field dependence of dislocation pinning in niobium alloys," Phys. Rev., Vol. 178, pp. 657-667, 1969.

39. B. I. Halperin and D. R. Nelson, "Resistive transition in superconducting films," J. Low Temp. Phys., Vol. 36, pp. 599-616, 1979.

40. J. E. Mooij, "Kosterlitz-Thouless transitions and two-dimensional superconductors," in Advances in Superconductivity, Vol. 100 of "NATO Advanced Study Institute Series B; Physics," edited by B. Deaver and J. Ruvalds Plenum, New York, pp. 433-474, 1983.

41. P. A. Bancel and K. E. Gray, "Search for vortex unbinding in two-dimensional superconductors," Phys. Rev. Lett., Vol. 46, pp. 148-152, 1981.

42. D. H. Kim, A. M. Goldman, J. H. Kang, and R. T. Kampwirth, "Kosterlitz-Thouless transiton in $\mathrm{Tl}_{2} \mathrm{Ba}_{2} \mathrm{CaCu}_{2} \mathrm{O}_{8}$ thin films," Phys. Rev. B, Vol. 40, pp. 8834-8839, 1989.

43. N.-C. Yeh and C. C. Tsuei, "Quasi-two-dimensional phase fluctuations in bulk superconducting $\mathrm{YBa}_{2} \mathrm{Cu}_{3} \mathrm{O}_{7}$ single crystals," Phys. Rev. B, Vol. 39, pp. 9708-9711, 1989.

44. S. Vadlamannati, Q. Li, T. Venkatesan, W. L. McLean, and P. Lindenfeld, "Enhanced Kosterlitz-Thouless transition in $\mathrm{YBa}_{2} \mathrm{Cu}_{3} \mathrm{O}_{7-\mathrm{x}} / \mathrm{PrBa}_{2} \mathrm{Cu}_{3} \mathrm{O}_{7-\mathrm{x}}$ multilayers as a measure of two-dimensionality," Phys. Rev. $B$, Vol. 44, pp. 7094-7097, 1991.

45. Y. Matsuda, S. Komiyama, T. Terashima, K. Shimura, and Y. Bando, "Disappearance of Hall resistance in oneunit-cell-thick $\mathrm{YBa}_{2} \mathrm{Cu}_{3} \mathrm{O}_{7-\mathrm{d}}$ : Evidence of free vortex-antivortex excitation," Phys. Rev. Lett., Vol. 69, pp. 3228-3231,. 1992.

46. D. P. Norton and D. H. Lowndes, "Transport propeties of ultrathin $\mathrm{YBa}_{2} \mathrm{Cu}_{3} \mathrm{O}_{7-d}$ layers: Evidence for twodimensional vortex fluctuations," Phys. Rev. B., Vol. 48, pp. 6460-6464, 1993. 